\title{
THE PROBLEM OF FAMILY AND LEGAL CONSEQUENCES OF REASSIGNMENT IN THE CONTEXT OF MARITAL AND PARENTAL RELATIONSHIP
}

\author{
Vadim O. Sirotkin \\ Ulyanovsk State University, Ulyanovsk, Russian Federation \\ Svetlana V. Lukashevich \\ Ulyanovsk State University, Ulyanovsk, Russian Federation
}

\begin{abstract}
Introduction: currently, the problem of ensuring the rights of sex changeers is being actively discussed at the international and national levels. Also important is the balance between the personal interests of citizens in need of changing their gender and public interests, including their family members. Therefore, the authors of a civilistic work set the goal of studying the effects of changing gender on family relationships, identifying related problems and suggest ways to solve them. Methods: the methodological basis of this study is a set of methods of scientific knowledge, among which the main methods are systematic, analysis and comparative law. Results: the author's position grounded in his work is based on the legislation and the opinions of the competent scientific community on the issue of resolving problems arising in family legal relations when one of the participants changes sex. Based on a legal analysis of the norms of Russian and international law, questions are raised about the possibility of preserving marital and family relations when one of the spouses changes sex, and to ensure the protection of the rights of children. Conclusions: as a result of the study, it was established that the current legislation has a number of collisions and gaps that need to be resolved as soon as possible.
\end{abstract}

Key words: gender reassignment, state registration of gender reassignment, marriage, family transformation, parent-child relationship.

Citation. Sirotkin V.O., Lukashevich S.V. The Problem of Family and Legal Consequences of Reassignment in the Context of Marital and Parental Relationship. Legal Concept, 2019, vol. 18, no. 2, pp. 94-98. (in Russian). DOI: https://doi.org/10.15688/lc.jvolsu.2019.2.15

\section{ПРОБЛЕМА СЕМЕЙНО-ПРАВОВЫХ ПОСЛЕДСТВИЙ ИЗМЕНЕНИЯ ПОЛА В КОНТЕКСТЕ СУПРУЖЕСКИХ И РОДИТЕЛЬСКИХ ПРАВООТНОШЕНИЙ}

\author{
Вадим Олегович Сироткин \\ Ульяновский государственный университет, г. Ульяновск, Российская Федерация \\ Светлана Владимировна Лукашевич \\ Ульяновский государственный университет, г. Ульяновск, Российская Федерация
}

Введение: в настоящее время проблема обеспечения прав лиц, сменивших пол, активно обсуждается на международном и национальном уровнях. Немаловажным остается соотношение границ личных интересов граждан, нуждающихся в перемене своей половой принадлежности, и общественных интересов, в том числе членов их семьи, в связи с чем авторами в работе цивилистического характера поставлена цель исследования - изучение последствий изменения пола субъектами семейных правоотношений, выявление связанных с этим проблем и предложение путей их решения. Методы: методологическую основу данного иссле- 
дования составляет совокупность методов научного познания, среди которых основное место занимают методы системности, анализа и сравнительного правоведения. Результаты: обоснованная в работе авторская позиция опирается на законодательство и доктринальные разработки по вопросу разрешения проблем, возникающих в семейных правоотношениях при изменении пола одним из его участников. На основании правового анализа норм российского и международного права поднимаются вопросы о возможности сохранения брачно-семейных отношений при изменении пола одним из супругов и обеспечения защиты прав детей. Выводы: в результате исследования установлено, что в действующем законодательстве имеется ряд коллизий и пробелов, которые нуждаются в скорейшем разрешении.

Ключевые слова: перемена пола, государственная регистрация перемены пола, брак, трансформация семьи, родительско-детские отношения.

Цитирование. Сироткин В. О., Лукашевич С. В. Проблема семейно-правовых последствий изменения пола в контексте супружеских и родительских правоотношений // Legal Concept = Правовая парадигма. 2019. - T. 18, № 2. - C. 94-98. - DOI: https://doi.org/10.15688/lc.jvolsu.2019.2.15

\section{Введение}

На сегодняшний день степень развития медицины сделала возможным изменение биологического пола человека путем гормонального лечения и хирургической операции [7, c. 26]. Впервые такие операции были проведены в 1953 г. в Марокко и Дании [2, с. 3]. Лидирующее положение в этой области занимает Таиланд. В России полная статистика о количестве проводимых операций не публикуется, они осуществляются в различных городах страны [5, с. 19].

Вопрос правовых последствий изменения пола в настоящее время по-прежнему остается недостаточно урегулированным российским законодательством и является дискуссионным для отечественной правовой науки и правоприменительной практики, что обусловливается рядом как доктринальных, так и технико-юридических причин.

Половая переориентация является причиной возникновения большого количества правовых проблем в институте брака, в частности, если лицо изменило пол, уже будучи в брачно-семейных отношениях.

\section{Доктринальные концепции}

\section{определения юридической судьбы} брака, в котором один из супругов изменил половую принадлежность

Следует отметить, что семейное законодательство не содержит норм, определяющих юридическую судьбу такого брака, в связи с чем в правовой науке предлагаются различные концепции.
Например, предлагается рассмотрение перемены пола в качестве «социальной смерти» и объявление такого гражданина умершим в судебном порядке, что в результате обусловило бы прекращение брака соответствующим решением суда $[6$, с. 70]. Однако данная концепция идет вразрез с целью названной процедуры: лицо объявляется умершим в случае, если обстоятельства дают основания предполагать его биологическую смерть. Кроме того, в рамках этого предложения не решается вопрос о круге субъектов, которые полномочны обратиться в суд с таким заявлением, а также не учитывается весь комплекс правовых последствий данного акта.

Объявление сменившего пол гражданина умершим нарушало бы комплекс прав и законных интересов как его самого, так и других граждан: он освобождался бы от алиментных обязательств, носящих сугубо личный характер; также это повлекло бы возникновение наследственных правоотношений, так как гражданским законодательством не предусмотрена иная конструкция определения судьбы имущества, а также прав и обязанностей объявленного умершим лица, и т. д. Более того, это дало бы основание для возникновения ряда социально-обеспечительных отношений для членов его семьи.

Не менее труднореализуемой является концепция, в соответствии с которой предлагается брак с лицом, изменившим пол после его заключения, трансформировать в «иной союз между однополыми людьми, ведущими общее хозяйство, воспитывающими общих детей, но не выполняющими ролей мужа и жены по отношению друг к другу» [3, с. 57]. 
Данное предложение основывается на компаративном исследовании опыта применения института гражданского союза в ряде государств, занимающего промежуточное положение между фактическим и официально зарегистрированным браком и доступного для заключения между лицами как разного, так и одного пола.

Однако российское законодательство не предусматривает объединения такого рода, и внедрение данного института требует точного определения правовой природы отношений между его субъектами: регулировать их нормами семейного права не представляется возможным, поскольку они противоречат его смыслу ввиду совпадения по основным признакам с брачными (кроме признака пола); разработка же такой формы объединения в рамках гражданского законодательства не позволяет решить ряд вопросов неимущественного характера, в том числе вопрос судьбы детей при их наличии, что в совокупности со сложившимися политико-правовыми условиями делает реализацию данной концепции нецелесообразной.

Далее необходимо отметить, что брак с лицом, изменившим пол после его заключения, нельзя признать недействительным [2, c. 6], поскольку ст. 27 Семейного кодекса РФ (далее - СК РФ) не предусматривает в качестве основания для применения данной формы прекращения брачных правоотношений перемену пола одним из супругов; к тому же признание брака недействительным носит ретроспективный характер и прекращает его с момента заключения, в то время как он, по общему правилу, с юридической точки зрения заключается с соблюдением всех необходимых условий, в том числе и относящихся к полу супругов.

В.Г. Алейниченко предлагает прекращать подобный брак путем расторжения [1, c. 40]. Однако для осуществления этого предложения необходимо волеизъявление хотя бы одного из супругов, чего даже при смене пола одним из них может и не последовать. Из этого следует, что половая переориентация супруга не является правопрекращающим фактом, и в результате возникает однополый союз, в то время как российское семейное право, исходя из положений ст. 1 и ст. 12 СК РФ, базируется на фундаментальном начале разнополости субъектов брачных правоотношений.

Это доктринальное противоречие может быть преодолено либо путем пересмотра основополагающих начал отечественного семейного права, что представляется недопустимым с точки зрения национальной идеи России вариантом, либо путем дополнения списка оснований прекращения брака, предусмотренного ст. 16 СК РФ, фактом изменения пола одним из супругов с распространением на него действия положений о расторжении брака в части правовых последствий, поскольку данная конструкция наиболее объективно отражает правомерный характер как самого факта смены пола лицом, так и брачно-семейных отношений, существовавших до их «трансформации» в однополый союз.

Следует указать, что прекращение супружеских отношений в рассматриваемом случае не противоречит нормам международного права, в частности ст. 8 Конвенции о защите прав человека и основных свобод 1950 г., а также подтверждается практикой Европейского суда по правам человека, исходящего в данном вопросе из позиции, что регулирование вопроса о правовых последствиях изменения пола отдается в значительной степени на усмотрение государств, в том числе и в сфере семейно-правовых отношений.

\section{Влияние смены пола гражданином на детско-родительские отношения с его участием}

Иным важным вопросом в рамках обозначенной проблемы является влияние факта изменения пола лицом на его родительские права и обязанности. Следует указать, что сам факт смены пола одним из родителей не имеет самостоятельного значения для родительских правоотношений, не влечет изменения прав и обязанностей по смыслу положений ст. 19 Гражданского кодекса РФ и ст. 70 Федерального закона «Об актах гражданского состояния», что также подтверждается фактом отсутствия в СК РФ изменения пола одним из родителей в качестве основания для лишения родительских прав либо ограничения в них. Более того, в соответствии с п. 2 ст. 54 СК РФ каждый ребенок имеет право жить и 
воспитываться в семье, право знать своих родителей, право на их заботу, право на совместное с ними проживание. Это распространяется и на статус усыновителя, в то время как ст. 127 СК РФ устанавливает запрет на усыновление лицам, состоящим в однополом браке по законодательству иностранного государства.

В юридической науке существует концепция, в соответствии с которой предлагается включить в ст. 69 СК РФ в качестве дополнительного основания для лишения родительских прав «произведение операции по изменению пола» ввиду того, что это может влиять на формирование у несовершеннолетних детей нетрадиционных сексуальных установок [8, с. 271], однако она не учитывает вероятность того, что это может навредить интересам ребенка в силу, например, наличия обоюдной устойчивой эмоциональной привязанности и отсутствия фактов уклонения родителя от его обязанностей и злоупотребления правами. Данное предложение в целом не учитывает самой правовой природы лишения родительских прав, являющегося, что подтверждает позиция Конституционного суда РФ, крайней мерой ответственности за совершение родителями виновного правонарушения в отношении своих детей [4], в качестве какого изменение родителем пола рассматриваться не может.

В данном вопросе нужно руководствоваться необходимостью наилучшего обеспечения интересов детей, что предусмотрено п. 1 ст. 3 Конвенции о правах ребенка 1989 г., дающим основание полагать, что они превалируют и над интересами самих родителей, изменивших пол. В этой связи действующее семейное законодательство предоставляет возможность ограничения таких лиц в родительских правах, поскольку транссексуализм в соответствии с Международной классификацией болезней 10-го пересмотра относится к классу психических расстройств и расстройств поведения, а значит для реализации данной возможности необходимо только подтверждение факта опасности оставления ребенка с изменившим пол родителем (например, ввиду психотравмирующей обстановки), однако это требует учета особенностей каждого отдельного случая. Также ограниченно- му в родительских правах по данному основанию лицу должны быть предоставлены возможности общения и восстановления психологического контакта с ребенком, а также право ходатайствовать перед судом об отмене данного ограничения в случае устранения для него оснований.

\section{Выводы}

Подводя итог сказанному, хотелось бы отметить, что нынешний уровень правового регулирования вопроса семейно-правовых последствий смены пола является недостаточным для того, чтобы разрешить существующие коллизии и восполнить пробелы в статусе изменивших пол лиц, пронизывающие значительную часть семейного законодательства и оттого порождающие множественность в правоприменительной практике. Однако при решении этого вопроса следует исходить в первую очередь из общечеловеческих ценностей, искать справедливый компромисс между частными и публичными интересами, чтобы равно не допустить необоснованных, дискриминирующих правоограничений для указанных граждан и нарушений существующего в Российской Федерации правопорядка.

\section{СПИСОК ЛИТЕРАТУРЫ}

1. Алейниченко, В. Г. Гражданско-правовая индивидуализация физических лиц в Российской Федерации : дис. ... канд. юрид. наук / Алейниченко Вячеслав Геннадьевич. - Ростов н/Д, 2006. - 191 с.

2. Горская, Е. Ю. Правовые проблемы изменения пола в Российской Федерации / Е. Ю. Горская // Семейное и жилищное право. - 2015. - № 4. - С. 3-6.

3. Малеина, М. Н. Изменение биологического и социального пола: перспективы развития законодательства / М. Н. Малеина // Журнал российского права. - 2002. - № 9. - С. 52-59.

4. Определение Конституционного Суда РФ от 16.11.2006 № 476-О «Об отказе в принятии к рассмотрению жалобы гражданки Бородий Елены Николаевны на нарушение ее конституционных прав и конституционных прав ее несовершеннолетнего сына положениями статей 69 и 71 Семейного кодекса Российской Федерации». - Доступ из справ.правовой системы «КонсультантПлюс».

5. Палькина, Т. Н. Проблемы реализации права на изменение пола / Т. Н. Палькина // Семейное и жилищное право. - 2010. - № 6. - С. 18-21. 
6. Степанов, Д. И. Правовые проблемы, связанные с изменением пола человека / Д. И. Степанов // Законодательство. - 2000. - № 11. - С. 70.

7. Шаблий, Д. С. К вопросу о законодательной регламентации порядка осуществления изменения пола // Семейное и жилищное право. -2012. № 1. - С. 26-28.

8. Яковлева, Е. А. Особенности правового положения лиц, сменивших пол в период брака / Е. А. Яковлева // Вестник экономики, права и социологии. - 2015. - № 4. - С. 268-271.

\section{REFERENCES}

1. Aleinichenko V.G. Civil-law Individualization of Individuals in the Russian Federation. Cand. jurid. sci. abs. diss. Rostov on Don, 2006. 191 p. (in Russian).

2. Gorskaya E.Yu. Legal Problems of Sex Transformation in the Russian Federation. Semeinoe i zhilishchnoe pravo, 2015, no. 4, pp. 3-6. (in Russian).

3. Maleina M.N. Changing of the Biologic and Social Sex: Prospekts of the Legislation's Development.
Zhurnal rossiyskogo prava, 2002, no. 9, pp. 52-59. (in Russian).

4. Determination of the Constitutional Court of the Russian Federation of November 16, 2006 No. 476$O$ "On Refusal to Accept Complaints from Citizen Borodiy Elena Nikolaevna for Violation of her Constitutional Rights and Constitutional Rights of her Minor Son by the Provisions of Articles 69 and 71 of the Family Code of the Russian Federation". Access from Reference Legal Sistem “Consultant Plus". (in Russian).

5. Pal'kina T.N. Problems of the Implementation of the Right to Change Sex. Semeinoe i zhilishchnoe pravo, 2010, no. 6, pp. 18-21. (in Russian).

6. Stepanov D.I. Legal issues related to gender reassignment. Zakonodatelstvo, 2000, no. 11, p. 70. (in Russian).

7. Shabliy D.S. On the issue of legislative regulation of the procedure for the implementation of sex change. Semeinoe i zhilishchnoe pravo, 2012, no. 1, pp. 26-28. (in Russian).

8. Yakovleva E.A. Legal Status of Individuals Who Changed Sex at a Time of Marriage. Vestnik ehkonomiki prava $i$ sociologii, 2015, no. 4, pp. 268-271. (in Russian).

\section{Information about the Authors}

Vadim O. Sirotkin, Student, Ulyanovsk State University, Goncharova St., 40/9, 432970 Ulyanovsk, Russian Federation, vadimsirotkin01@mail.ru, https://orcid.org/0000-0002-4236-4633

Svetlana V. Lukashevich, Candidate of Sciences (Jurisprudence), Associate Professor, Department of Civil Law and Process, Ulyanovsk State University, Goncharova St., 40/9, 432970 Ulyanovsk, Russian Federation, luminica@list.ru, https://orcid.org/0000-0003-1226-7733

\section{Информация об авторах}

Вадим Олегович Сироткин, студент, Ульяновский государственный университет, ул. Гончарова, 40/9, 432970 г. Ульяновск, Российская Федерация, vadimsirotkin01@mail.ru, https://orcid.org/ 0000-0002-4236-4633

Светлана Владимировна Лукашевич, кандидат юридических наук, доцент кафедры гражданского права и процесса, Ульяновский государственный университет, ул. Гончарова, 40/9, 432970 г. Ульяновск, Российская Федерация, luminica@list.ru, https://orcid.org/0000-0003-1226-7733 